\title{
Psychological Counseling To Reduce Adolescent Stress In Child Development Agency
}

\author{
Rini Lestari \\ Faculty of Psychology, Universitas Muhammadiyah Surakarta \\ Rini.Lestari@ums.ac.id
}

\begin{abstract}
Adolescent is transition phase from childhood to adulthood. Recently, teenagers undergo significant change and development in all aspects, either physical, social, or psychological. One of the developments is on their sexual and hormonal organs, where they would be interested with their sexual counterparts, have desire to date, and yearn for sexual experience. Unlimited sexual activity result in unwanted pregnancy, early marriage, and abortion. If sexual intercourse or teenage pregnancy occurs and the girl's side did not willing to accept this occurrence, they could press charges and convict the boy's side through legal processes. The convicted teenagers will be rehabilitated and placed in Child Development Agency (CDA). In Child Development Agency, they suffer from psychological issues such as stress indicated by difficulty to sleep, anxiety, loneliness, short-tempered and easily offended, daydreaming, blaming others, inability to concentrate and so on. These conditions should be intervened by giving psychological counseling-as one of the interventions. The study aims to examine the effects of psychological counseling to reduce stress among teenagers in CDA.The subjects are 10 male and female teenagers who undergo rehabilitation in CDA. The counseling is conducted four times to each subject individually. The analysis is conducted quantitatively by Wilcoxon Ranks Test and qualitatively. The results show significant decrease of stress after counseling. Subjects feel happy because they are understood, given attention, and being listened to thus reducing their loneliness, and it also decrease their duration of daydreaming by doing many activities given by the counselor. Relaxation given in counseling process also help them to sleep, reduce anxiety and increase their concentration. $60 \%$ subjects could understand the meaning behind the occurrence they suffer from and are willing to try to be someone better and would not repeat the same mistake.
\end{abstract}

Keywords: psychological counseling, stress, adolescent

\section{INTRODUCTION}

Adolescent is transition phase from childhood to adulthood. Recently, teenagers undergo significant change and development in all aspects, whether physical, social, or psychological. Physically the body experiences growth and development, the body and sexual organs are also experiencing growth, as well as with the sexual hormones. This change affects adolescent sexual behavior. They would be interested with the sexual counterparts, have desire to date, and yearn for sexual experience. Unlimited sexual activity result in unwanted pregnancy, early marriage, and abortion. If sexual intercourse or teenage pregnancy occurs and the girl's side did not willing to accept this occurrence, they could press charges and convict the boy's side through legal processes. The convicted teenagers will be rehabilitated and placed in the Child Development Agency (CDA). Teenagers who undergo rehabilitation at the Child Development Agency becomes no longer free to live. They often feel bored, resentful, disappointed, angry, home sick,depression, difficulty to sleep, anxiety, loneliness, short-tempered and easily offended, daydreaming, blaming others, inability to concentrate and so on. These symptoms indicate that adolescents arestress.

Stress is a person's judgment of a challenging life event (Lazarus \& Folkman, 1984). Stress is the emotional and physical strain of the caused as a result of our response to what happens around us. Stress is a multidimentional phenomenon which is focused on dynamic relationship between the individual and the environment (Patel, 2014). Stress is an experience that every person and the fact that can not be avoided. However,not all situations are labeled negatively impact stress (Emeke, 2006). It should be noted that some degree of stress can be effective on increasing and improving individuals performance, but high rate of stress would followed by numerousconsequences, such as mental and physical illness, sleep disorders, restlessness, irritability, forgetfulness, fatigue, individual reduced resistance, headaches, poor concentration, memory impairment and reduce in problem solving abilities (Wong, 1999).

Stress can be divided into primary appraisal (individual evaluation of the challenges, threats or harm caused by an event) and secondary appraisal (individual assessment of the capability and resources to cope with the events) (Lazarus \& Folkman, 1984). Stress can be sourced from individuals, family and community, financial, education, relationships with others, the loss of a loved people and traumaticevents (Pakan, 2015; Sarafino, 2006). Generally, stress is characterized by cognitive symptoms (low self-esteem, inadequate, not able to concentrate, forgetfulness), emotional (anxiety, 
fear,irritability, depressed, anxious), behaviors (withdra wal, stuttering talk, crying, impulsive, refusing to cooperate, smoking, drugs, alcohol, loss of appetite /overeating), physical (headaches, neck, forehead, muscles, ulcers, blood pressure, sweating, heart, stroke) (Emeke, 2006; Taylor, 2009).

Some interventions can be used to reduce stress, including relaxation (Patel, 2014), narrative writing (Danoff-Burg, Mosher, Seawell, Agee, 2010), neuro-linguistic programming (Wake, \& Leighton, 2014; Maslakpak, Farhadi, Fereidoni , 2016); and counseling (Ray, 2007; Regehr, Glancy, Pitts, 2013; Rana, 2014; Rozario, Baroi, Islam, 2017). Counseling is an intervention to help others by using specific skills for a specific purpose. The purpose of counseling is to help clients changingthe ways of thinking and behavior so they feel better (Geldard and Geldard, 2011).

In this study, counseling is selected as an intervention toreduce stress because adolescents need for attention, understanding, comprehension, friend that they can trustand support from others. The number of caregivers at CDA is minimal, and also the ability and time of the caregiver is very limited. Therefore, the purpose of this study is to know the effect of psychological counseling to reduce the adolescents stress in CDA. The study aims to examine the effects of psychological counseling to reduce adolescent stress in CDA. The hypothesis is psychological counseling can reduce adolescent stress in CDA.

\section{METHOD}

This research is using one group pre-test post-test design. The subjects are 10 male and female teenagers who undergo rehabilitation in CDA. Subjects are 15-17 years old and living in CDA. The counseling is conducted four times to each subject individually. Counseling is given oncea week, 2 2,5 hours/ session. Levels of stress are measured using DASS (Depression Anxiety Stress Scale). The analysis is conducted by Wilcoxon Ranks Test and qualitatively.

\section{Results and Discussion}

Adolescence is a stage of self and require the support and guidance of adults, especially parents. However, in this case $80 \%$ of subjects came from a broken home or a parent who failed to give attention and affection to their children. The subjects look for attention and affection from others like a friend or a girlfriend. Relationship with boy/girlfriend often too freely resulting in unwanted pregnancies and abortions. Relation with peers give a bad influence because the friends who come from broken home family and lack of attention and affection. They seek the pleasures of life and tend to be no rules. The bad influence of friends such as smoking, drinking, drunkenness, risk sexual behavior and sexual harassment. Free sexual intercourse and sexual harassment resulted in women being perceived as victims by the general public and especially women's parents. These conditions resulted in the victim's parents ask for to marry the victim, if it does not want to be responsible then reported to the authorities. There are the victim's parents who directly prosecute legally so that the perpetrators should be punished, although they had sexual intercourse in love. Furthermore, these teenagers were awarded a penalty in CDA for several months.

In CDA the subjects will be rehabilitation and get physical, social, mental guidance. Reality, they fell bored, disappointed, anxious, homesick, lonely, embarrassed, blaming others, difficulty concentrating, sleeplessness, nightmares, itching, dizziness, weakness, crying, withdrawal or aggressive/angry.This condition indicates that the subjects are stress. The DASS (Depression Anxiety Stress Scale) show that the stress is a severe (mean : 29.2). Generally, the symptoms of adolescents stress are low self-esteem, decreased activity, sleep disorders, diet, lack of self-control, poor social relationships (Schraml, Perski, Gossi, Sarnecki, 2011).Stress is caused by physical condition (lack of educational facilities, clean water, crowded, supporting facilities skills activities), social (lack of number and skills caregivers/teachers, bad friend) and psychological (attention, understanding, support). This is consistent with previous studies that stress caused by individuals, environment and relationships with others (Pakan, 2015; Sarafino, 2006).

Teenagers will try to solve the problem with coping, include the problem focused coping/instrumental and emotion focused coping/palliative (Rice, 1999). Coping is all cognitive and behavioral efforts to master, reduce, or tolerate demands (Folkman and Lazarus, 1994). Nevertheless, the subjects tend to coping in a negative way, not assertive/silent, aggressive, avoidance/withdrawal and denial/supresssion. This condition is influenced by the low level education, so they feel inability and inferiority. In fact, they want to get help, attention, understanding and social support, especially from the caregiver but the caregivers have less time and competence so they tend to overcome the stress with less constructive. The intervention can be given to reduce adolescents stress is psychological counseling. Psychological counseling is a technique to help individuals with psychological problems usingspecific skills, such as active listening, empathy, support, paraphrase, no judge, no assumptions and advice. In addition, psychological counseling can reduce stress and improve the quality of human life (Pakan, 2015).

Counseling provided to adolescents individually for 4 sessions. The DASS measurement before counseling (pre-test) shows that subjectsare severe stress (mean: 29.2). After a counseling session is completed (post-test) the level of stress is moderate (mean: 23.7). This can be seen in Table 1. 
Table 1. Distribution of Subjects

\begin{tabular}{|c|c|c|c|c|c|c|}
\hline $\begin{array}{l}\text { Subje } \\
\text { ct }\end{array}$ & $\begin{array}{l}\mathrm{Ag} \\
\mathrm{e}\end{array}$ & $\begin{array}{l}\text { Educati } \\
\text { on }\end{array}$ & $\begin{array}{l}\text { Gend } \\
\text { er }\end{array}$ & $\begin{array}{l}\text { Pre- } \\
\text { test } \\
\text { score }\end{array}$ & $\begin{array}{l}\text { Post- } \\
\text { test } \\
\text { score }\end{array}$ & $\begin{array}{l}\text { Differen } \\
\text { ce }\end{array}$ \\
\hline S1 & 17 & SMP & Male & 26 & 20 & 6 \\
\hline $\mathrm{S} 2$ & 17 & SMP & Male & 27 & 20 & 7 \\
\hline S3 & 16 & SMP & Male & 28 & 20 & 8 \\
\hline S4 & 16 & - & Male & 31 & 23 & 8 \\
\hline IS5 & & & Male & 30 & 23 & 7 \\
\hline & 16 & SD & & & & \\
\hline IS6 & 15 & SD & Male & 29 & 24 & 5 \\
\hline S7 & 15 & - & Male & 33 & 29 & 4 \\
\hline S8 & 17 & SD & $\begin{array}{l}\text { Femal } \\
\text { e }\end{array}$ & 29 & 28 & 1 \\
\hline S9 & 16 & $\mathrm{SD}$ & Male & 32 & 24 & 8 \\
\hline IS10 & 15 & SD & Male & 27 & 26 & 1 \\
\hline $\mathrm{S} 1$ & 17 & SMP & Male & 26 & 20 & 6 \\
\hline \multicolumn{4}{|c|}{ Average } & 9.2 & 3,7 & 5,5 \\
\hline
\end{tabular}

This study showed that counseling was able to reduce the adolescents stress in CDA. The analysis with Wilcoxon Ranks Test obtained the $\mathrm{Z}=-2.555 ; \mathrm{p}=$ 0.011 ( $\mathrm{p}<0.05)$. There is a significant difference in stress levels between before and after counseling is given. This research can prove the hypothesis that psychological counseling can reduce the level of adolescents stress in CDA. The decline scores is ranging between $1-8$, while the average decrease is 5,5 .

Thisstudy reinforces previous research that one of the interventions to reduce stress is counseling (Ray, 2007; Regehr, Glancy, Pitts, 2013; Rana, 2014; Rozario, Baroi, Islam, 2017). Through counseling process subjects feel caring and understanding of counselors who have been less from the caregiver. This condition makes the subjects become to believe and are more open to express all their problems. Counselor willingness to listen and understand all the complaints without judgment made to feel comfortable and create higher quality relationships. Relationship between the counselor and subjects make it easy to provide assistance and directing the subject's attitudes, thoughts and behaviors become more constructive. Kaplan, Tarvydas,

Gladding (2014) statesthat the success of the counseling process does require the presence of a counselor, active listening, empathy and no judgment.

The subjects report that they are happy in this counseling process because they get a trusted friend to listen the problem so that to reduce the loneliness. Some of the activities conducted jointly by the counselor during the counseling process such as progressive muscle relaxation is also helping the subjects to reduce anxiety, and help sleepand concentration. Progressive muscle relaxation is done to make relaxed that stimulates the pituitary gland to secrete endorphins (Nopadow et. al, in Rokade, 2011).These endorphins can further provide a calming effect as well as feelings of happiness (Goldstein and Lowry, in Rokade, 2011).

Another positive change is $60 \%$ of the subjects get wisdom positive of events experienced, no want to repeat the same mistakes, want to be better, apologize and reciprocation especially to the parents. This condition arises because during the counseling process subjects are asked to recount all experience in life and encourage the subject to realize that in a negative experience there is a positive experience/lessons to be grateful. Subjects realize get togetherness, skills, new friends, independent, considered the family and realize the error. These conditions reduce the tension that have been felt and create stress. This study is consistent with Miller (Snyder \& Lopez, 2002) that the individual whose life is able to be grateful and positive thinking will avoid the stress and pressures of life.

This study shows that subjects change cognitive, affective and behavioral aspect. In cognitive aspects, subjects capable to realize the capabilities (such as painting, singing) and will develop the ability to get the money. Subjects can understand that their behavior have been destroyprecisely. They will try to improve themselves to be better behavior. The subjectsare also grateful because God still give the opportunity to change for the better in order to determine their future. In affective aspects, loneliness tends to decrease because subjects are aware of the existence of other friends and caregivers. Subjects enhace relationship with others and realize their mistake. In behavior aspects, subjects try no cry when experiencing grief and will be pray. Physically,trouble sleeping and a desire to hurt others also to decrease. Trouble sleeping and musclestanding tensions felt overcome by relaxation exercises as taught by counselors.

This study shows that there are three subjects (S7, S8, S10) are still severe stress despite showing a decrease in the score. S7 is less educated and does not pass primary school so it is difficult to understand the questions and instructions of the counselor. The counseling process to S7 lasts longer than other subjects and the final results arenot as targeted. S8 had refused to continue the relaxationexercises because when she closed eyes appeared shadows of people who were killed that makes it very afraid. S8 is a woman who always remember the incident of murder ever commited. Therefore the subject needs counselor'ssupport and guidance. S8 also want tomove women CDA to get female friends. While S10 still feels right bored because always remember his family and the family demands to go home and work back. This makes the subject repeatedly attempted to escape with a reason to immediately work for the sake of the family. 


\section{CONCLUSIONS AND SUGGESTION}

Adolescentsin CDA are severe stress that are indicated by symptoms bored, disappointed, anxious, homesick, lonely, embarrassed, blaming others, difficulty concentrating, sleeplessness, nightmares, itching, dizziness, weakness, crying, withdrawal or tend to be aggressive/anger. They also have high DASS score. Theywant anyone could listen to complaints and provide care, support, but not obtained from caregivers. Therefore, psychological counseling should be given to these adolescents to reduce the level of stress. The research showed that psychological counseling can reduce stress levels significantly. Subjects were able to realize the mistake that have been done and got a positive lessons while in CDA. Subjects also experienced positive cognitive, affective, behavioral and physical changes. However, there are 3 subjects with severe stress. This was influenced by education, sex and family demands.

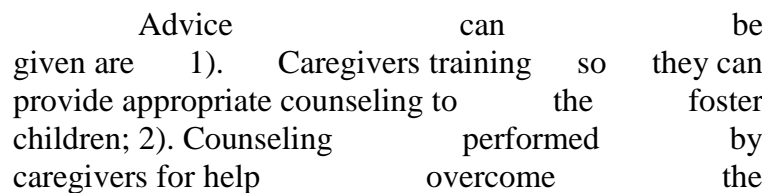
problems; 3). Subjects more open to express the problem to caregivers.

\section{REFERENCE}

$\mathbf{R}$

Danoff-Burg, S., Mosher, C. E., Seawell, A.H, Agee, J.D. (2010). Does Narrative Writing Instruction Enhance the Benefits of Expressive Writing? Anxiety Stress Coping, 23 (3), 341-352.

Emeke, E. A. (2006). Stress Syndrome: C ause, Symptoms and Coping Strategy. International Jornal of African \& African American Studies, 5 (2), 48-58.

Geldard, K. \& Geldard, D. (2005). Practical Counseling Skills. An Integrative Approach. Palgrave Macmillan.

Kaplan, D. M, Tarvydas, V. M, \& Gladding, S. T. (2014). A Vision for The Future of Counseling: The New Consensus Definition of Counseling. Journal of Counseling \& Development, 92 (3), 366-372.

Lazarus, R. S.\& Folkman, S. (1984). Stress, Appraisal and Coping. New York: Springer.

Maslakpak, M. H, Farhadi, M., Fereidoni, J. (2016). The Effects of Neuro-linguistic Programming on Occupational
Stress, in Critical Care Nurses. Iranian Journal of Nursing and Midwifery Research, 21 (1).

Pakan, J. A. (2015). Counseling To Reduce Stress and Anxiety: A Mixed Methods Study. New York: State University of New York. http: //digitalcommons@ @rockport.edu.

Patel,M.P. (2014). A Study to Assess theEffectiveness Muscles Progressive Relaxation Therapy on Stress Among Staff Nurses Working in Selected Hospitals at Vadodara City. Journal of Nursing and Health Science, 3 (3), 34-59. http : www.iosrjournals.org

Rana, M. (2014). Stress Among Adolescents and The Roleof Counseling in Managing it: A Review. Indian Journal of Health and Wellbeing, 5 (7), 99-104.

Ray, D. (2007). Two Counseling Inteventions to Reduce Teacher-Child Relationship Stress. Professional School Counseling, 10 (4), 428-440.

Regehr, C., Glancy, D., Pitts, A. (2013). Interventions to Reduce Stress In University Students: A review and Meta-analysis. Journal of Affective Disorders, 148 (1), 1-11. Doi: http//dx.doi.org /10.1016/j.jad.2012.11.026

Rice, L. P. (1999). Stress and Health. 3 Edition. Pacific Grove, California: Brooks/Cole Publishing Company.

Rokade, P. B. (2011). Release of Endomorphin Hormone and Its Effects on Our Body and Moods: A Review. International Conference on Chemical, Biological and Environment Sciences, 436-348.

Rozario, L. G, Baroi, A. A, Islam, S. (2017). Impact of Psychological Counseling onPosttraumatic Stress Disorder Victims of Rana Plaza Tragedy. International Journal of Psychology and Counseling, 9(5), 2633. Doi: 10.5897 / IJPC2017.0490

Sarafino, E. (2006). Health Psychology: Biopsychology Interaction (5th Edition). New York: John Willey and Sons. Inc.

Schraml, K., Perski, A., Gossi, G., Sarnecki, M. S. (2011). Stress Symptoms Among Adolescents: The Role of the Subjective Psychosocial, Conditions, Lifestyle and Self Esteem. Journal of Adolescence, 34, 987-996.

Snyder, C. R.\& Lopez, S. J. (2002). Handbook of Positive Psychology. New York: Oxford University Press.

Taylor, S. E. (2009). Health Psychology. 7th Edition. New York: McGraw-Hill, Inc.

Wake, L. \& Leighton, M. (2014). Pilot Study Using Neurolinguistic Programming (NLP) in Post-Combat PTSD. Mental Health Review Journal, 19 (4), 251-265.

Wong, P.T.P. (1990). Measuring Life Stress. Stress Medicine, 6, 69-70. 